\title{
Development of Austenite Fe Alloy for Melted Zinc Coating Facilities Using the DV-Xa Methods
}

\author{
Min-Sook Baek ${ }^{1}$, Kyeong-Cheol Baek ${ }^{2}$, Yoon-Ja Kim², Dong-Joo Yoon ${ }^{1 *}$
}

${ }^{1}$ Center for practical Use of Rare Materials, Sunchon National University, Suncheon 540-742, Korea

${ }^{2}$ SAMWOO ECO, LTD. 545-801, Korea

DOI: $10.36347 /$ sjet.2021.v09i01.001

| Received: 16.01.2021 | Accepted: 25.01.2021 | Published: 29.01.2021

*Corresponding author: Dong-Joo Yoon

Abstract

In this study, the material used in the hot dip galvanizing equipment was poorly corrosion-resistant, so it was performed to solve the cost and time problems caused by equipment replacement. The theoretical calculation was performed using the DV-X $\alpha$ method (Discrete Variational Local-density approximation method). The alloy (STS316L) of the equipment currently used has a austenite phase. Therefore, the theoretical calculation was performed by applying Fm-3m, which is a cubic structure. The new alloy was chosen by designing theoretical values close to existing materials. Considering elements that contribute to corrosion, most have high prices. Therefore, the design was completed by adjusting the content using only the components of the reference material in the theoretical design. The final design alloys were chosen as SWA6. Designed SWA6 were dissolved and prepared using an induction furnace. After the heat treatment process was completed, the corrosion rate of the alloys was confirmed by using the potentiodynamic polarization test. The surface of the prepared alloys were processed horizontally and then polished to \# 1200 using sand paper to perform potentiodynamic polarization test. 316L: 0.9599 mpy (mils / year), SWA6: 0.828 mpy, alloys designed than 316L had a lower corrosion rate. Therefore, the designed alloy was expected to have better erosion resistance.

Keywords: Erosion resistant, Fe-based alloys, Austenite phase, DV-X $\alpha$ method, Induction furnace, Potentiodynamic polarization test, Corrosion rate, Continuous hot dipping line.

Copyright (C) 2021 The Author(s): This is an open-access article distributed under the terms of the Creative Commons Attribution 4.0 International License (CC BY-NC 4.0) which permits unrestricted use, distribution, and reproduction in any medium for non-commercial use provided the original author and source are credited.

\section{INTRODUCTION}

Compared to other processes such as electrical coating, dry coating and so on, a continuous melted coating method can facilitate coating of a thick surface and offers relatively lower costs for increased coating thickness. For this reason, it is being widely used in the industry, and the amount of production is gradually increasing. In particular, zinc-coated steel plates are very frequently used for automobile steel plates $[1,2]$.

Because the zinc melted coating steel plate has a sacrificial effect on the steel plate as well as the excellent anticorrosion characteristics of zinc, it has been very widely used for some time, and with the emerging need for rust-proofing of automobile structures, there has been a sudden increase in the global demand for zinc coating steel plates. As the result of producing coated steel plates from high tension steel plates, the amount of tension delivered to the pot roll unit is increased, so to increase the amount of production, we must increase the line speed. As such, the need to upgrade the pot roll unit has emerged.
In Korea, the continuous melting coating line facility was introduced from advanced countries such as Germany and Japan. In 1990, Korean industries began to localize the related parts, and by mid-2000, the facility was successfully localized. But compared to lifespans of advanced materials, the lifespan of domestic products is about 4 times shorter, and is also much poorer in terms of anticorrosion and strength [3].

A pot roll unit is used to vertically raise the strip painted through the coating bath after passing through the furnace and the snout in the continuous melting coating line, so that the amount of coating can be properly controlled through the air knife system. Depending on the composition of the coating bath for each steelwork, temperature is maintained at $450^{\circ} \mathrm{C} \sim 680^{\circ} \mathrm{C}$ and the characteristics of coated steel plates are established by injecting materials such as $\mathrm{Zn}$, $\mathrm{Al}, \mathrm{Mg}, \mathrm{Si}$ and so on. Depending on the composition of the coating bath and its temperature, different materials are used for pot roll frames, sink rolls, correcting rolls, and stabilizing rolls, and different surface processing 
methods are also used for each type of roll. At each steelwork, an integrated type of frame or U-frame, or separated type of frame is used for pot roll units. Figure 1 partially illustrates parts for the pop roll unit. This is the facility that is required for controlling the amount of coating in the continuous melted coating line at the steelwork. Each steelwork has its own management criteria, but 5 sets of pot roll units are used in turn after some maintenance works.

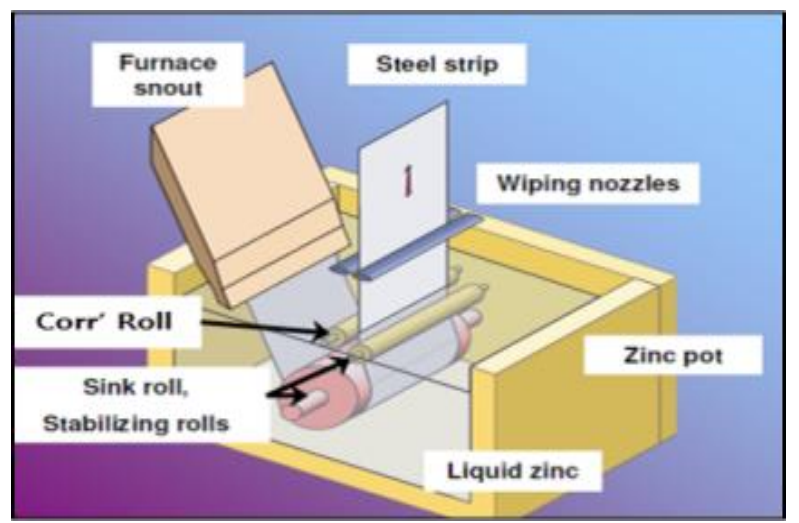

Fig-1: Composition of Pot Roll Unit

As was mentioned earlier, the continuous melted coating line facilities are being localized. Some Korean casting companies are manufacturing products with the ratio of raw materials used in the advanced countries, but their anticorrosion characteristics and strength are relatively poor, making it necessary to develop domestic products with equivalent performance. Figure 2 shows a part of the pot roll unit that has corroded.

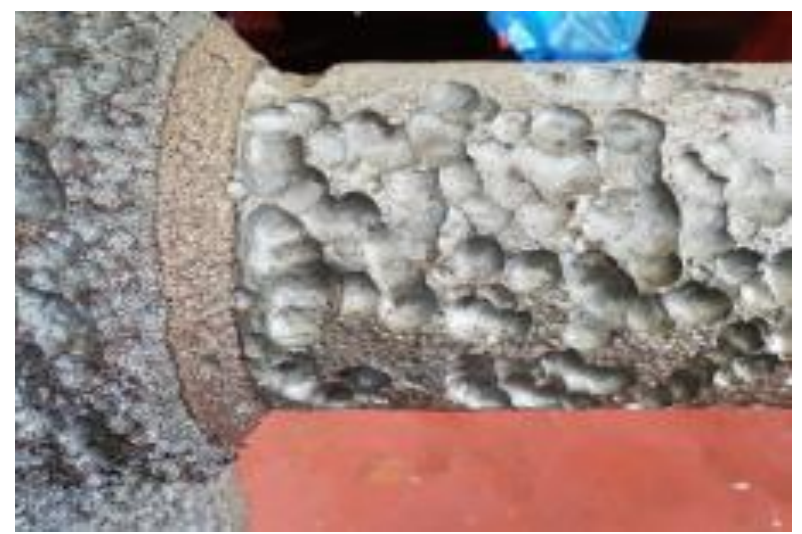

Fig-2: Corroded Pot Roll Unit

In this study, the authors aim to design an austenite-based $\mathrm{Fe}$ alloy for continuous melted coating line facilities that can address the existing problem of domestic product (STS316 series) such as anticorrosion characteristics and strength using theoretical calculations, and then analyze the characteristics of the resulting product.

\section{Fe-based Alloy Design}

The DV-X $\alpha$ method currently used in the research project is a type of semi-empirical molecular orbit calculation method completed by Adachi. In this method, characteristically, a molecular orbit function is obtained in the form of mathematical function which is a solution for the Schrodinger wave equation in the chemical environment. Orbit of every atom including core electrons is applied to the calculation as a mathematical function to minimize the errors. Based on Discrete Variational(DV) methods, multi integral is quantitatively performed to calculate various physical quantities from principle 1. Finally, due to the characteristics of local density approximation, the calculation efficiency is relatively high. Calculation is repeated until the electronic density(final value) on each atom obtained by performing Mullikan interpretation of the molecular orbits results is in accordance with the electron density(initial value) assumed before obtaining the mathematical basis function [4].

If other metallic elements are included in the Fe base alloy with an austenite structure, to assess the energy status, the DV-X $\alpha$ methods are used. After preparing a cluster that can be a mode of the alloy, Fe is placed around each element to derive the $\mathrm{Md} / \mathrm{Bo}$ values for each element. Using the theoretical Md/Bo values, alloys are newly designed.

Iron nickel with cubic structure is applied to the theoretical calculation. Unit Cell/Space group information [5,6] is provided in Table 1.

Table-1: Information of Austenite Fe for cluster model used

\begin{tabular}{|l|l|}
\hline Chem. Name & Iron nickel(1/1) \\
\hline Unit Cell $(\mathrm{a}, \mathrm{b}, \mathrm{c})$ & $3.57,3.57,3.57$ \\
\hline Space Group & Fm-3m \\
\hline Crystal System & Cubic \\
\hline Site $(\mathrm{x}, \mathrm{y}, \mathrm{z})$ & Fe $0,0,0$ \\
\hline
\end{tabular}

After collecting the information suitable for the theoretical calculation, the DV-X $\alpha$ method is used to select and prepare the minimum structure to be calculated. For the final cluster, 5 entities are added for $\mathrm{Fe}$ and calculation elements $(\mathrm{X})$ are added around them to form a Fe6X6 (a total of 12) structure. The results are illustrated in Figure 3.

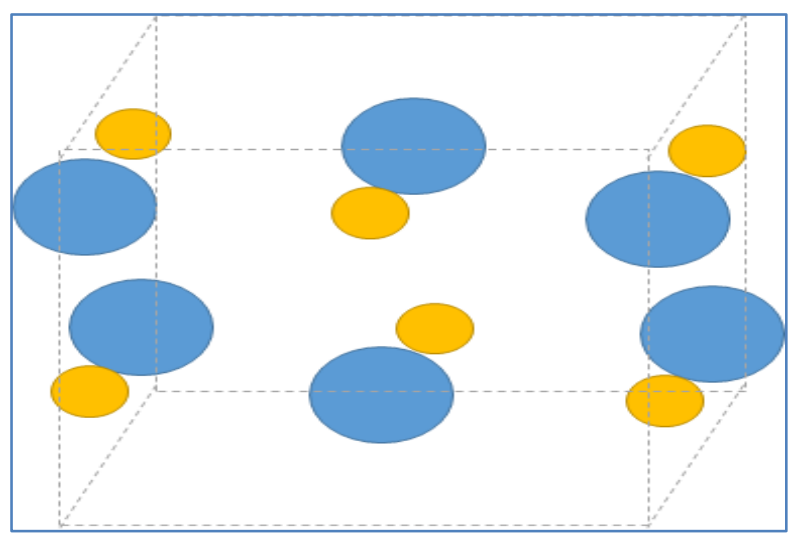

Fig-3: Cluster model employed in the calculation, Fe6-X6 cluster 
Min-Sook Baek et al., Sch J Eng Tech, Jan, 2021; 9(1): 1-7

$\mathrm{Fe}$ is a transitional metallic element. There are strong covalent bonds in d orbits for metallic bonds. Thus, since orbit $\mathrm{d}$ has greater impacts on the property than orbits $\mathrm{s}$ and $\mathrm{p}$, the energy value for orbit $\mathrm{d}$ is calculated, and if the element does not have orbit d, then the level of orbits $\mathrm{s}$ and $\mathrm{p}$ for the outermost electrons is calculated.

In this study, two parameters are used. The first one is d-orbital energy for the element alloy, and it refers to the energy level where level $\mathrm{d}$ of the replaced $\mathrm{X}$ is changed; hereinafter, this is referred to as $\mathrm{Md}$. The second one is bond order (hereinafter Bo). The electron overlapping population among atoms is obtained by using Mullikan's population analysis method. The Bo is an index indicating the strength of the bond between atoms, and it is relevant to the physical properties of the alloy [4, 7-10].

Every theoretical calculation assumes a pure state with no external energy or bonding. Table 2 presents the $\mathrm{Md} / \mathrm{Bo}$ values resulting from substituting for each alloy element.

Table-2: List of Md and Mo values for various elements of Austenite Fe

\begin{tabular}{|l|l|l|}
\hline fe-x & Md & Bo \\
\hline $\mathrm{Al}$ & 0.42 & 0.1221 \\
\hline $\mathrm{C}$ & 0.85 & 0.2069 \\
\hline $\mathrm{Co}$ & 0.0257 & 0.3201 \\
\hline $\mathrm{Cr}$ & 0.4658 & 0.5394 \\
\hline $\mathrm{Cu}$ & 1.2492 & 0.125 \\
\hline $\mathrm{Fe}$ & 0.2009 & 0.4773 \\
\hline $\mathrm{Mg}$ & 0.8206 & 0.4649 \\
\hline $\mathrm{Mn}$ & 0.5623 & 0.4977 \\
\hline $\mathrm{Mo}$ & 4.7034 & 0.4273 \\
\hline $\mathrm{N}$ & 0.6444 & 0.178 \\
\hline $\mathrm{Ni}$ & 1.8285 & 0.1587 \\
\hline $\mathrm{Nb}$ & 0.638 & 0.254 \\
\hline $\mathrm{Si}$ & 0.034 & 0.1831 \\
\hline $\mathrm{Ti}$ & 1.0803 & 0.957 \\
\hline $\mathrm{W}$ & 0.8327 & 1.4084 \\
\hline
\end{tabular}

To set the reference value before designing a new alloy, the existing 316L alloy's average theoretical value is calculated using the following formula [7].

$$
\begin{aligned}
& \overline{M d}=\sum_{i=1}^{n} X_{i} \cdot(M d) i \\
& \overline{B o}=\sum_{i=1}^{n} X_{i} \cdot(B o) i
\end{aligned}
$$

Xi: Alloy i component mole fraction

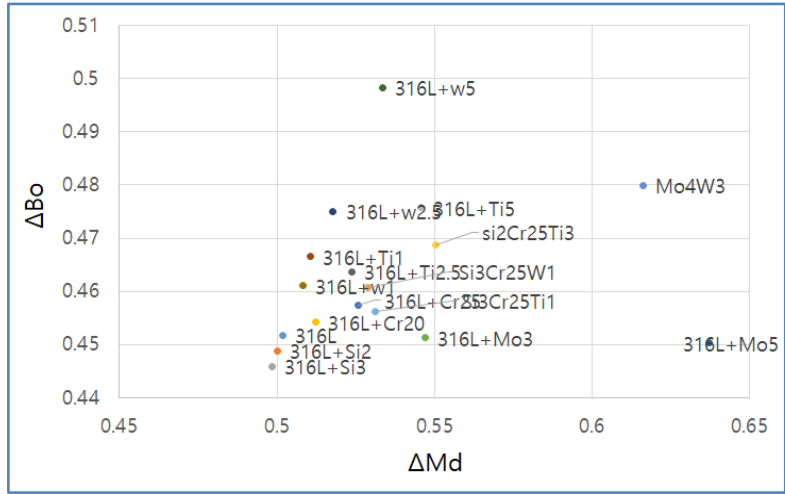

Fig-4: $\overline{M a}-\overline{B c}$ Diagram of Design Alloys and Developed Alloy

Due to the large size of the facility, a new alloy is selected considering high raw materials costs and excluding the expensive ones ( $\mathrm{Ti}, \mathrm{Pt}, \mathrm{Pd}$, etc.) that can help to prevent corrosion[11-12]. To achieve similar mechanical properties such as strength, elongation rates and so on, the existing elements are used. The biggest setback for the existing alloy is anticorrosion characteristics. Since there are not such significant problems in strength and hardness, the design aims to maximize the anticorrosion characteristics by slightly sacrificing strength and hardness. While reducing the amount of an alloy element that can improve strength, the design proceeds by increasing the amount of an alloy element that can improve the anticorrosion characteristics.

Based on the domestic STS316L standards, materials with excellent heat resistivity and strength, such as $\mathrm{Ti}, \mathrm{Cu}$ and $\mathrm{Nb}$, are used to proceed with $1^{\text {st }} / 2^{\text {nd }}$ alloy design processes. In addition, $\mathrm{Cr}, \mathrm{Si}, \mathrm{Mo}, \mathrm{Ti}$ and $\mathrm{W}$ are set to design about 20 types of alloys. For these approximately 20 types of alloys, Figure 4 illustrates average $\mathrm{Md} / \mathrm{Bo}$ values.

After designing about 20 types of alloys, the movement location depending on the amount of each component is assessed, and thus the characteristics of the most dominant elements - Ti and $\mathrm{W}$ - are assessed.

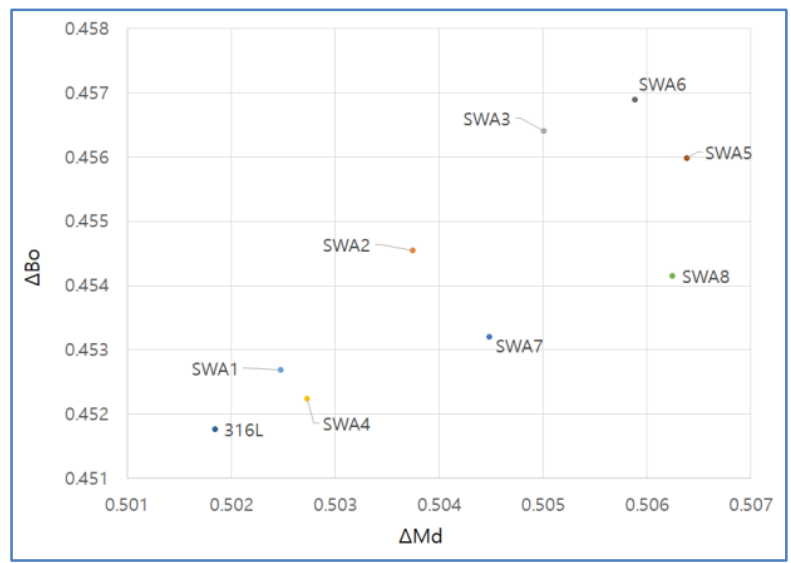

Fig-5: $\overline{M r}-\overline{B c}$ diagram of Design alloys

(SWA1 SWA8) and alloy 316L 
Figure 5 illustrates the results for the average theoretical Md/Bo values for the newly designed alloy and the domestic alloy. The higher the average Md and Bo values are, the higher the energy is. According to the research findings, mechanical properties such as strength or hardness are improved as a result [13-15]. But on the contrary, the higher the energy is the more unstable it gets. So, the anticorrosion characteristics can be compromised.

Based on the STS316L, the research relies on the theoretical values only, and uses the approximate value to design a total of 8 types of alloys. Ti and $\mathrm{W}$ offer high strength and heat resistivity, but at high costs. So, by performing fine tuning, the amount of these elements was limited to less than $1 \%$.

Finally, as $\mathrm{Ti}$ and $\mathrm{W}$ show the maximal theoretical values even with minimal amount, the alloy SWA6 (Sam Woo Austenite No.) is selected.
The finally selected alloy SWA6 is directly manufactured using the induction melting furnace. The resulting alloy's transformation temperature is measured, and it is thermally processed. After the thermal processing, the alloy goes through fine tissue observation, hardness testing, and tensile strength testing and potentiodynamic polarization testing for a comparative analysis.

\section{Austenite Fe alloy manufacturing}

The alloy designed using a theoretical calculation method is melted in a vacuum by using the vacuum induction melting furnace. Each alloy's dissolved components are described in Table 3. Before the induction melting process, to lower the high melting point of Mo, Fe and Mo are mixed at a ratio of 3:1 to manufacture the master alloy in a vacuum arc melting furnace with argon fills. Vacuum level is max $10^{-6}$, and dissolving is done at least three times by flipping forward and backward.

Table-3: Austenite Based Alloy 316L, SWA6's Dissolved Components

\begin{tabular}{|l|l|l|l|l|l|l|l|l|l|}
\hline (wt\%) & Fe & Cr & Si & Mn & Mo & Ni & C & X & Y \\
\hline 316L & Bal. & $16-18$ & $\leq 1$ & $\leq 2$ & $2-3$ & $12-15$ & $\leq 0.03$ & - & - \\
\hline SWA6 & Bal. & $16-18$ & $\leq 1$ & $\leq 2$ & $2-3$ & $12-15$ & $\leq 0.03$ & $<0.3$ & $<0.3$ \\
\hline
\end{tabular}

For the vacuum induction melting process, various types of test samples are assumed, so a circular rod shaped casting mold with $30 \Phi$ is used. To prevent the casting mold from being broken due to temperature differences when being injected into the melting bath, the casting mold is preheated to $800^{\circ} \mathrm{C}$ before melting.

Each type of material is injected into the melting furnace in turn, and the material with low ratio is placed at the bottom so that it does not emerge to the surface of the melting bath. Due to the large amount of dissolving, $\mathrm{Fe}$ is additionally injected in a total of two sessions. When the melting bath is ready after the induction melting process starts, the preheated casting mold is placed into the melting furnace, and then the melted liquid is injected into it.

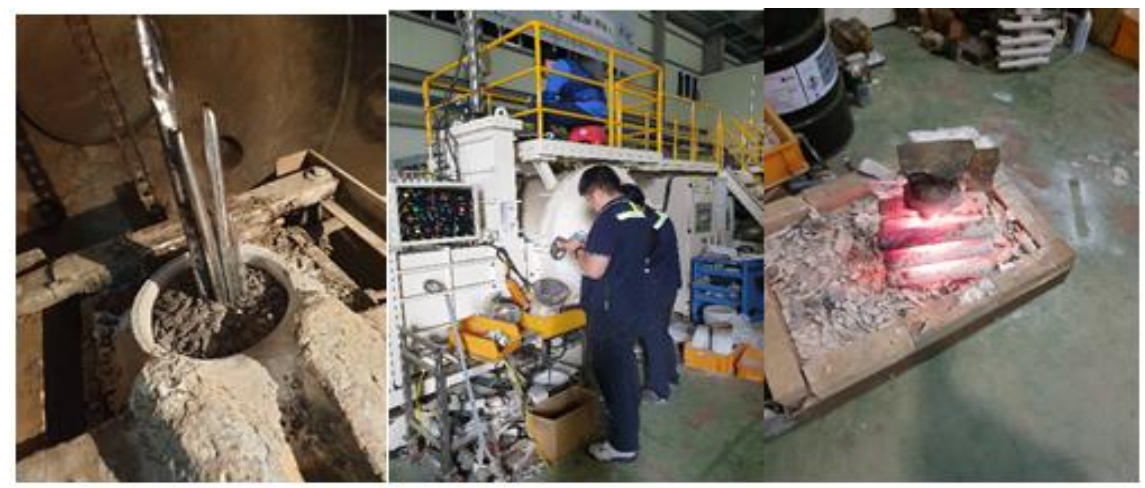

Fig-6: Manufacture of Alloy Using Induction Melting

Figure 6 illustrates the induction melting furnace and the melting works, and the type of alloy manufactured therefrom. Casting molds with 30Ф are used. Each time, a total of $14 \mathrm{~kg}$ is melted.

\section{RESULTS AND ANALYSIS}

Composition analysis and phase change analysis After the vacuum and air induction melting process, the $316 \mathrm{~L}$ and the SWA6's components are indicated in Table 4 as follows.

Table-4: Alloy composition after casting (316L, SWA6)

\begin{tabular}{|l|l|l|l|l|l|l|l|l|l|}
\hline (wt \%) & Fe & Cr & Si & Mn & Mo & Ni & C & X & Y \\
\hline DCS9 & 63.8 & 17.1 & 0.52 & 1.6 & 2.6 & 13.8 & 0.03 & - & - \\
\hline SWA6 & 63.4 & 16.78 & 0.4 & 1.4 & 2.43 & 12.28 & 0.038 & 0.04 & 0.3 \\
\hline
\end{tabular}


After that, to assess the thermal processing temperature, the manufactured alloy 316L and SWA6 are used for TMA analysis, and the transformation temperature and thermal expansion coefficient are measured and presented in Figure 7. In a TMA analysis, temperature is raised by 5 degrees in every minute while the weight is set to $1 \mathrm{~N}$ and measurements are made up to max temperature of 1200 degrees in the argon gas environment.
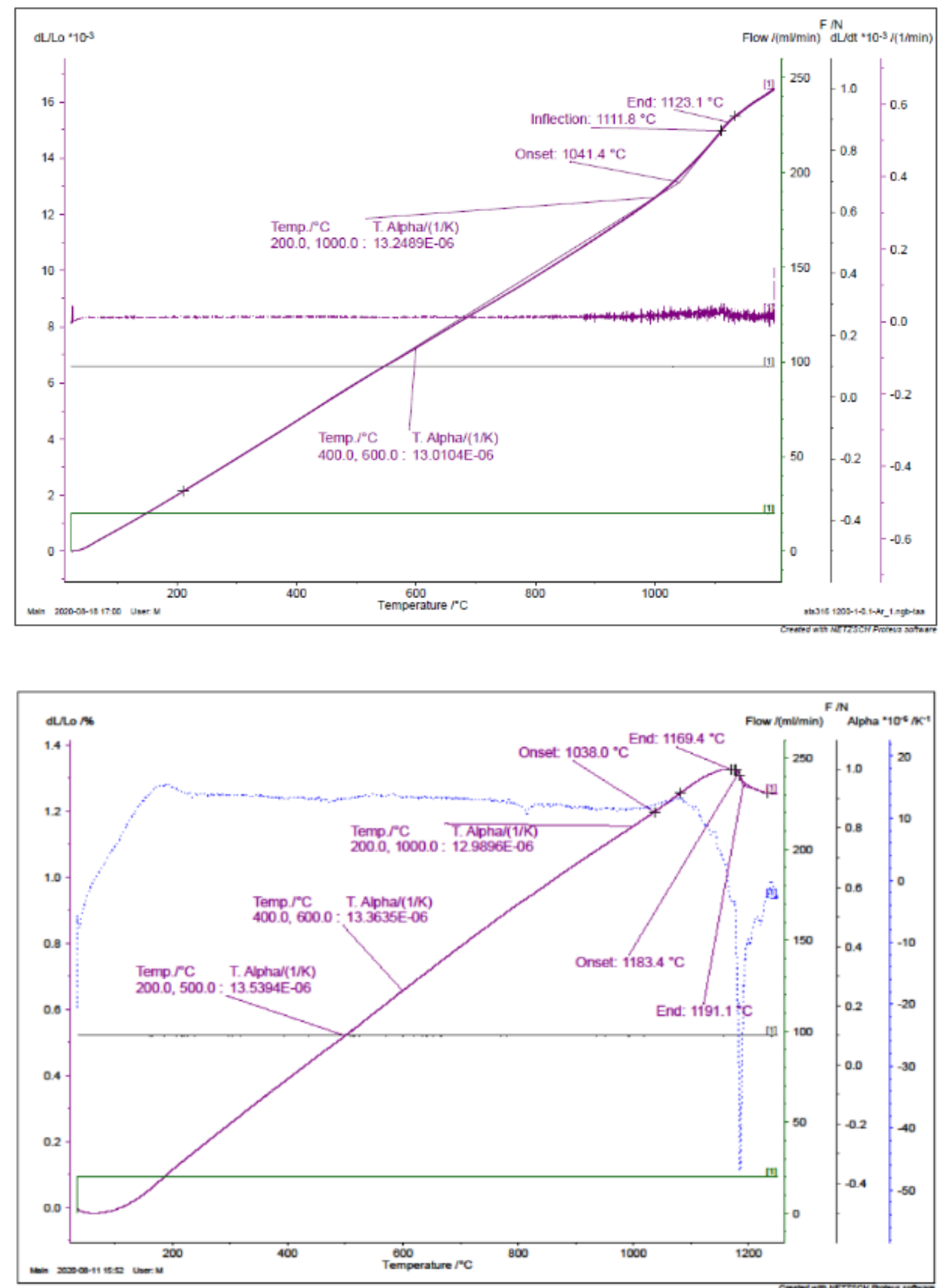

Fig-7: TMA Analysis of 316L(left) and SWA6(right)

For the thermal analysis condition of $316 \mathrm{~L}$, temperature is set to $1200^{\circ} \mathrm{C}$, with an increase of $1 \mathrm{~K}$ and force of $0.1 \mathrm{~N}$ in the Argon environment. At the melting point of $5 \% \mathrm{Al}-\mathrm{Zn}, \quad 500^{\circ} \mathrm{C}$, there is no sign of transformation; at $400 \sim 600^{\circ} \mathrm{C}$, the thermal expansion coefficient is measured as $13.01 \mathrm{E}-06(1 / \mathrm{K})$. The sign of transformation is observed around $1111.8^{\circ} \mathrm{C}$.
For SWA6, phase change starts around $1040^{\circ} \mathrm{C}$ and becomes noticeable around $1170^{\circ} \mathrm{C}$. At the melting point of $5 \% \mathrm{Al}-\mathrm{Zn}, 500^{\circ} \mathrm{C}$, there is no sign of transformation; at $400 \sim 600^{\circ} \mathrm{C}$, the thermal expansion coefficient is measured to be $13.36 \mathrm{E}-06(1 / \mathrm{K})$, which is similar to $13.01 \mathrm{E}-06(1 / \mathrm{K})$ for the STS $316 \mathrm{~L}$. Based on the TMA results, the thermal processing conditions are set to staying at $1100^{\circ} \mathrm{C}$ for 3 hours and cooling afterward (solution treatment). 


\section{Organization and mechanical property analysis}

Figure 8 shows the optical microscopic image (500x) of microstructures found in the $316 \mathrm{~L} / \mathrm{SWA} 6$ that have completed thermal processing after vacuum induction melting. After cutting, mounting, and rough side grinding $(1 \mu \mathrm{m})$, the etching liquid of glycerin
$45 \mathrm{ml}+\mathrm{HCL} 30 \mathrm{ml}+\mathrm{HNO} 315 \mathrm{ml}$ is used for etching. Due to the large amount of $\mathrm{Cr}$, etching is required immediately after grinding the rough side where $\mathrm{Cr}$ oxidation layers are formed. After soaking it in the etching liquid for 7 to 10 minutes, it is removed to be washed with alcohol.

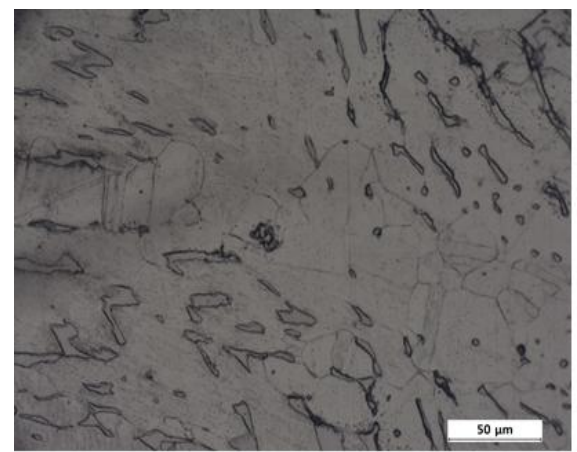

Fig-8: Optical Micro-structures 316L(Left)and SWA6(Right)(x500)

Both types of alloy seem to be a combination of austenite and ferrite. The $316 \mathrm{~L}$ shows a smaller crystal size than the SWA6. It seems that due to the effects of elements newly added to the SWA6, the crystal size becomes smaller.

To assess the mechanical properties, a hardness test and a tensile strength test are performed. For a hardness test, Vicker's hardness meter is used. Weight of $30 \mathrm{~g}$ is applied for a total of 5 measurements to get an average. Table 5 shows the values for 316L/SWA6.

As shown in the tissue photo, the hardness value for SWA6 is slightly lower than the $316 \mathrm{~L}$ due to large crystal sizes.

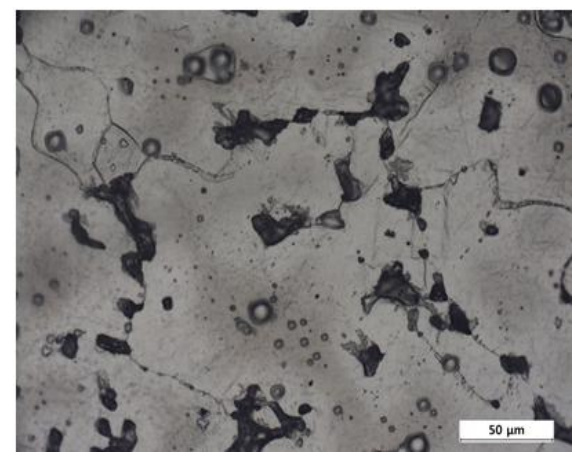

Table-5: Result of Vickers Hardness test

\begin{tabular}{|l|l|}
\hline & Vickers Hardness(HV) \\
\hline $316 \mathrm{~L}$ & 148.6 \\
\hline SWA6 & 142.8 \\
\hline
\end{tabular}

For a tensile strength test, the designed material, SWA6 is used. For a tensile strength test, KS B 0801 no. 6 (plane type) is used to manufacture a proportional test sample. For a tensile strength test, the JIS Z 2241 : 2011 test method is used. A total of 2 test samples were manufactured, and the test results are shown in Figure 9. Due to the limited number of test samples, for 316L, no tensile test is performed; it instead was compared with the generally used tensile strength.

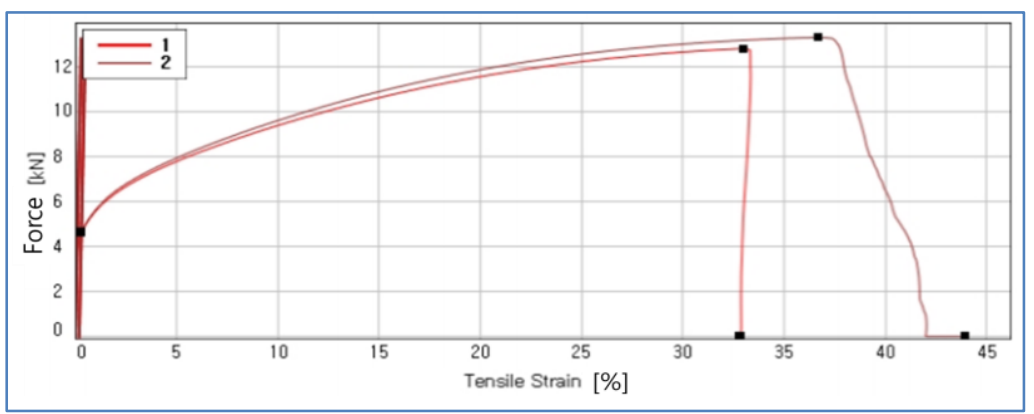

Fig-9: SWA6 Stress-strain Curves

The speed for the tensile test is set to 2mm/min. SWA6-1 tensile strength: $425.97 \mathrm{MPa}$, yield strength: $152.91 \mathrm{Mpa}$, elongation rate: $32.84 \%$, SWA62 tensile strength: $442.33 \mathrm{MPa}$, yield strength: 155.06 Mpa, elongation rate: $43.95 \%$. It is confirmed that the tensile strength requirement for $316 \mathrm{~L}$ alloy - $440 \mathrm{MPa}$ is met.

\section{Anticorrosion analysis}

First of all, to determine the anticorrosion characteristics, after thermal processing, the final sample's corrosion rate is measured in a potentiodynamic polarization test. As the electrolyte for the potentiodynamic polarization test, $0.9 \% \mathrm{NaCl}$ is used, with a scan rate of $5 \mathrm{mV} / \mathrm{s}$, and the sample area size of $1 \mathrm{~cm}^{2}$ is used. Table 6 indicates each sample's corrosion rate, Icorr(current density) and Ecorr(Potential). Ecorr refers to the potential generated on the surface of test sample that is corroded near the standard electrode in an open circuit condition. The lower the value of Icorr in the entire potential areas, the better anticorrosion characteristics it has [16-18]. 
To determine the anticorrosion characteristics, after thermal processing, the final sample's corrosion rate is measured in a potentiodynamic polarization test. Regarding the corrosion rate, compared to $0.9599 \mathrm{mpy}$ for the $316 \mathrm{~L}$, the newly designed SWA6 shows better results, $0.828 \mathrm{mpy}$. Also, this is deemed to be the result of additional elements added.

Table-6: Corrosion rate of the samples

\begin{tabular}{|l|l|}
\hline & Corrosion rate (mpy) \\
\hline 316L & 0.9599 \\
\hline SWA6 & 0.828 \\
\hline
\end{tabular}

\section{CONCLUSION}

In this study, to improve the anticorrosion characteristics and strength of domestic products that have been applied to the continuous melting zinc coating lines, a DV-X $\alpha$ method, one of the theoretical calculation methods, is used to design and manufacture a new type of alloy, and a comparative analysis is performed to yield the following conclusions. For the final results, the new alloy SWA6 is designed accordingly. According to a characteristics analysis, it offers better anticorrosion characteristics than the 316L, and the hardness/tensile strength tests also show that the designed and manufactured alloy has good quality.

1. Assuming the theoretical method used for alloy design, if a new alloy is designed with a smaller theoretical Bo value than the existing materials, a relatively lower hardness value is achieved for the newly designed SWA6 than in the domestic products, and thus we can confirm that the hardness value is similar to the trends of the theoretical Bo, with some slight differences.

2. There is a significant difference in the theoretical value observed after manufacturing actual alloy with ideal alloy compositions.

3. Among the theoretical calculation based designed alloys, the one finally selected shows similar tensile strength and hardness to the SWA6 and 316L. Its corrosion rate is excellent, as it only has a discrepancy of less than 0.1 mpy.

\section{ACKNOWLEDGMENT}

The paper is the result of research sponsored by the metropolitan collaborative industry project (regional initiative R\&D, project no. : P0006079).

\section{REFERENCES}

1. Lee HJ, Kim MS. Behavior of the Surface Precipitatio $\mathrm{n}$ of Manganese Oxides during Hot-dip Galvanizing. J ournal of the Korean institute of surface engineering. 2015;48(1):27-32.

2. Hong MH, Hwang GS, Chung JH. Microstructure of s urface defects observed on continuous hot-dip galvani zed and galvannealed coating steels. Journal of the Ko rean Institute of Metals and Materials(South Korea). 2 002 Jan;40(1):83-92.

3. Shin TS. Cost Comparisons between the Hot-dip Galv anizing and the Paintion for Structural Steel. Journal o $\mathrm{f}$ the Architectural and urban Institute. 2002;1:93-100.

4. Adachi H, Tsukuda M, Satoko C. Discrete variational $\mathrm{X} \alpha$ cluster calculations. I. Application to metal cluster s. Journal of the Physical Society of Japan. 1978 Sep $15 ; 45(3): 875-83$.

5. Metllofizkika.1972, 31, 73-77

6. Sumiyama K, Kadono M, Nakamura Y. Metastable bc c phase in sputtered $\mathrm{Fe}-\mathrm{Ni}$ alloys. Transactions of the Japan institute of metals. 1983;24(4):190-4.

7. Seifert K, Hafner J, Furthmuller J, Kresse G. The influ ence of generalized gradient corrections to the LDA o $\mathrm{n}$ predictions of structural phase stability: the Peierls d istortion in As and Sb. Journal of Physics: Condensed Matter. 1995 May 8;7(19):3683.

8. Furthmüller J, Käckell P, Bechstedt F, Kresse G. Extr eme softening of Vanderbilt pseudopotentials: Genera 1 rules and case studies of first-row and d-electron ele ments. Physical Review B. 2000 Feb 15;61(7):4576.

9. Ninomiya R, Yukawa H, Morinaga M, Kubota K. An electronic approach to the prediction of the mechanica 1 properties of magnesium alloys. Journal of alloys an d compounds. 1994 Nov 1;215(1-2):315-23.

10. Allred AL. Electronegativity values from thermochem ical data. Journal of inorganic and nuclear chemistry. 1961 Jun 1;17(3-4):215-21.

11. Jeon UT, Park YS. A study on the effects of N. Mo an $\mathrm{d} \mathrm{Ni}$ additions on the characteristics of passive film an $\mathrm{d}$ the improvement of corrosion resistance of $\mathrm{Fe}-\mathrm{Cr} \mathrm{m}$ artensitic stainless steel, The Korean Institute of Surfa ce Engineering. 1997;5(1997):61-2.

12. Lee JH, Kim MH, Hwang SK, Kwun SI. Improvemen $\mathrm{t}$ of $\mathrm{Zr}$-base alloy for nuclear reactor core materials ap plication by Mo addition. Journal of the Korean Instit ute of Metals and Materials. 2000;38(6):745-51.

13. Morinaga M, Kamado S. An electronic approach to th e prediction of the mechanical properties of aluminiu $\mathrm{m}$ alloys. Modelling and Simulation in Materials Scie nce and Engineering. 1993 Jan;1(2):151.

14. Baek MS, Yoon DJ, Kim BI. A Study on the Propertie $\mathrm{s}$ of Design for the Biomaterial Ti-Ag-Zr Alloys Usin g DV-X $\alpha$ Molecular Orbital Method. Korean Journal of Materials Research. 2014;24(4):175-9.

15. Baek MS, Kang PS, Baek KC, Kim BI, Yoon DJ. Des ign of Nickel Alloys Using the Theoretical Values Cal culated from the Electronic State Energies. Korean Jo urnal of Materials Research. 2015;25(11):642-6.

16. KT Oh, Sim HM, Hwang CJ, Kim KN. Propertise of TiAg alloy for dental application, J.Korean Soc. Dent. Mater. 2002;29(3): 221.

17. Fontana Mars Guy. Corrosion Engineering, 576, McG raw-Hill Book Company. 1987, 59-65.

18. Han JH, Lee KH, Shin MC. Corrosio Characteristics o f Titaniym Alloys for Medical Implant, Analytical sci. Technol. 1996; 9(2): 192. 